\title{
HISTÓRIA PÚBLICA E HISTÓRIA DA MÚSICA DO BRASIL E A CRIAÇÃO DO SITE A MÚSICA DE: HISTÓRIA PÚBLICA DA MÚSICA DO BRASIL
}

\author{
PUBLIC HISTORY AND HISTORY OF MUSIC IN BRAZIL AND THE \\ CREATION OF THE SITE THE MUSIC FROM: PUBLIC HISTORY OF \\ MUSIC IN BRAZIL
}

Daniel Lopes Saraiva ${ }^{38}$

\begin{abstract}
Public history has gained prominence in the historiographic milieu, at the same time that we have seen a dizzying growth in the publishing market, especially with regard to the relationship between history and biography. Therefore, the article proposed here aims to discuss some of the possible relationships between oral history, public history, history of the present time and history of music. For that, some books and a project that contemplates the relationship between academic studies on music and its reverberations beyond the university are analyzed. Finally, the project The music of: public history of music in Brazil, which aims to constitute a broad platform on the subject, and some points of the interview with the singer Edy Star made for the website The music of: history are presented. of Brazilian music are analyzed in the article.
\end{abstract}

\section{RESUMO}

A história pública tem ganhado destaque no meio historiográfico, ao mesmo tempo em que temos visto um crescimento vertiginoso no mercado editorial, principalmente no que concerne à relação entre história e biografia. Diante disso, o artigo aqui proposto tem como objetivo discutir algumas das possíveis relações entre história oral, história pública, história do tempo presente e história da música. Para isso, são analisados alguns livros e um projeto que contempla a relação entre os estudos acadêmicos sobre a música e suas reverberações para além da universidade. Por fim, são apresentados o projeto A música de: história pública da música do Brasil, que tem como objetivo constituir uma plataforma ampla sobre o tema, e os alguns pontos da entrevista com o cantor Edy Star feita para o site A música de: história pública da música do Brasil são analisados no artigo.

\section{KEYWORDS}

Public history, music, memory, oral history

\section{PALAVRAS-CHAVE}

História pública, música, memória, história oral

\section{Introdução}

\footnotetext{
${ }^{38}$ Doutor em História, Universidade do Estado de Santa Catarina: danielsaraiva_15@hotmail.com
} 
Nas últimas décadas, temos visto o crescimento no número de biografias e livros de história ao redor do globo. No Brasil não é diferente. Entre os personagens escolhidos, por diversas vezes destacam-se os músicos, compositores, intérpretes, empresários do cenário musical, grupos de artistas e movimentos musicais. Sejam autobiografias, sejam publicações escritas por um profissional, esses livros se avolumam nas estantes das livrarias $^{39}$. Para além disso, os documentários sobre a música brasileira também vêm ganhando destaque ao falar, por exemplo, de movimentos musicais como Coisa mais linda (2005), sobre a história da bossa nova, e Tropicália (2012), que aborda o movimento de mesmo nome; ou acerca de trajetórias individuais, como Raul - O início, o fim e o meio (2012) e Eu sou Carlos Imperial (2013); ou ainda narrando um evento marcante da nossa história, como o sucesso de público Uma noite em 67 (2010), que narra o festival da Rede Record daquele ano. Há também as minisséries e os filmes sobre personagens que fizeram parte da história da nossa música, como Maysa: quando fala o coração (2009), Dalva e Herivelto: uma canção de amor (2010) e Gonzaga: de pai para filho (2012) — este exibido primeiro no cinema e depois na televisão. Em comum, todos têm a característica de terem sido vinculados na emissora de maior audiência do país, a Rede Globo.

Mas de que forma essas obras ajudam na reelaboração da história da música brasileira? Para responder esta pergunta, observamos a publicação do livro do jornalista Ricardo Alexandre, A vida e o veneno de Wilson Simonal (2009), e a realização do documentário sobre a vida do artista, Ninguém sabe o duro que eu dei (2009), do mesmo ano. As duas obras, além de apresentarem a trajetória do cantor Wilson Simonal, abordam a questão da reelaboração da memória. Simonal foi considerado "colaborador" da ditadura ${ }^{40}$ e,

${ }^{39}$ Nas últimas décadas, foi lançada uma infinidade de livros ligados a trajetórias de indivíduos e grupos ligados à música. A Editora 34 tem em seu catálogo livros sobre os Festivais da Canção, Jovem Guarda, Os Mutantes e diversos outros títulos. A Editora Cobogó tem na coleção o livro do disco, em que discos célebres ganham uma edição escrita por um jornalista ou pesquisador da área. Entre os livros de memória, temos como exemplo os de André Midani, Rita Lee e César Camargo Mariano. E entre os artistas que foram biografados recentemente, temos Elis Regina, Fagner e Elza Soares. A lista é grande e seria impossível citar todos os nomes nesse momento.

${ }^{40}$ Essa colaboração até hoje não foi muito explicada pela historiografia. Apesar de o nome do artista estar presente em documento das forças armadas, não há o que explique como era essa colaboração (https://www.documentosrevelados.com.br/repressao/forcas-armadas/documento-do-exercito-revelanome-de-delatores-no-meio-artistico). 
na ocasião de sua morte, em junho de 2000, amargava um ostracismo. Após o lançamento do livro e do filme, a figura do artista foi redimensionada por meio de questões como a de ser um dos primeiros negros a fazer sucesso no Brasil e de ter tamanha desenvoltura nos palcos, aspectos que sobrepujaram a até então mácula de possível colaborador do regime militar, que assombrava sua trajetória.

Os trabalhos citados nos permitem ver de que forma a rememoração pode alterar a memória de trajetórias como essa. Cabe aqui ressaltar também a importância do trabalho do historiador Gustavo Alonso, que antes do boom de pesquisas sobre Simonal, defendeu, em 2007, sua dissertação no programa de pós-graduação em história da Universidade Federal Fluminense (UFF), intitulada Quem não tem swing morre com a boca cheia de formiga Wilson Simonal e os limites de uma memória tropical, que foi lançada em livro no ano de 2011.

Pensando no trabalho de Gustavo Alonso e de outras pesquisas no campo da história, cabe a pergunta: qual é o estado atual das pesquisas históricas sobre música brasileira?

Os estudos sobre a música no Brasil tiveram início nos anos 1980 e, na década seguinte, aumentaram exponencialmente. Silvano Fernandes Baia (2015, p. 18), em sua análise sobre os estudos da historiografia da música popular no país, diz que o campo, até hoje, vem buscando melhor posicionamento, pois as pesquisas estabelecidas até o fim do século XX versavam quase que exclusivamente sobre a música popular do Rio de Janeiro. O autor cita ainda que alguns movimentos musicais tinham um maior número de pesquisas, como a bossa nova e a tropicália, enquanto outras vertentes da música brasileira ganhavam pouco ou nenhum espaço nos estudos historiográficos. Ao abordar o conceito da sigla MPB, ele deixa claro que não se trata apenas de uma abreviação de música popular brasileira, uma vez que não engloba toda a música popular feita no país, mas, sim, um subconjunto dessa produção. A sigla surgiu na década de 1960 para designar um repertório que despontou na efervescência dos festivais e que foi se configurando um ponto de convergência entre bossa nova, canção engajada, gêneros tradicionais (como samba e baião) e, posteriormente, tropicalismo (Baia, 2015, p. 189). Como pode ser observado no trabalho de Baia, são esses movimentos da música brasileira os principais tópicos tratados nas pesquisas até os anos 
1990. Mesmo acenando para uma mudança, a década posterior foi discreta em relação à abertura de temáticas sobre a música popular brasileira, continuando a tratar como preponderantes aquelas cristalizadas pela elite cultural brasileira.

Mas por que os estudos sobre a MPB ganharam mais importância? Segundo Marcos Napolitano (2005, p. 7),

[...] a música tem sido, ao menos em boa parte do século XX, a tradutora de nossos dilemas nacionais e veículo de nossas utopias sociais. Para completar, ela conseguiu, ao menos nos últimos quarenta anos, atingir um grau de reconhecimento cultural que encontra poucos paralelos no mundo ocidental. Portanto, arrisco dizer que o Brasil, sem dúvida uma das grandes usinas sonoras do planeta, é um lugar privilegiado não apenas para ouvir música, mas também para pensar a música.

O autor ressalta ainda o lugar privilegiado que a música popular tem no Brasil, afinal, nela encontram-se mediações, fusões, encontros de diferentes etnias, religiões, classes e regiões, além de ser, por diversas vezes, tradutora de muitos dos nossos dilemas nacionais (Napolitano, 2005, p. 7). Indo ao encontro da fala de Napolitano, Alberto Moby Silva (2008, p. 48) destaca que a música popular, provavelmente mais do que outras manifestações culturais, tem papel fundamental na formação da identidade nacional, muito provavelmente pela sua inserção junto à camada média urbana da população. E para Miriam Hermeto (2012, p. 41), "analisar historicamente a canção popular brasileira é pensar nela como uma produção cultural, conformada e limitada pelas suas condições de produção, circulação, recepção pelos mais diferentes públicos e pelos muitos usos sociais que dela se pode fazer".

A partir da fala desses pesquisadores, fica evidente que a música tem espaço privilegiado no cotidiano da sociedade brasileira, sendo possível traçar parte da história cultural, política e comportamental a partir de uma canção, movimento musical ou trajetória.

Nos últimos anos, diversos historiadores têm não apenas pesquisado a música, mas também vêm ampliando o público leitor, dialogando com as memórias nacionais sobre o tema e produzindo pesquisas com processo de produção dialógica. Muitos deles, inclusive, trabalhando com história oral, o que faz com que grande parte desses trabalhos sobre a música brasileira tenham convergência com a história pública, que tem ganhado cada vez mais espaço institucional nos últimos anos no Brasil. Chamando atenção para a pluralidade da história pública, Ricardo Santhiago (2018, p. 326) cita que a "ida ao público [...] significou, em grande medida, uma busca por resguardar o valor do historiador, dos métodos de pesquisa 
histórica e de sua autoridade profissional frente a outros agentes e procedimentos potencialmente danosos à nossa cultura histórica”.

Muitos agentes dominaram as técnicas narrativas e, em alguns casos, criaram best-sellers de história popular, diversas vezes sem o rigor metodológico, sem as devidas citações e sem a preocupação com a narrativa apresentada. É claro que não pode ser feita uma generalização, mas essas situações têm cada vez mais se avolumado no mercado editorial. Para Santhiago (2018, p. 327), o papel do historiador tem se redesenhado no momento em que aspectos da experiência social atual, como a emergência do revisionismo, a polarização política, as ameaças à liberdade de cátedra e a ruptura democrática de 2016, "imbuíram à história pública de oferecer respostas socialmente relevantes às questões mais vivas do presente”. Ele chama atenção ainda para a importância da história oral no crescimento da história pública. De acordo com o historiador, foi a ela que na pósredemocratização e no registro acadêmico coube pensar o passado recente, tornando-se um dos canais de interlocução mais vigorosos entre a sociedade civil e os historiadores baseados nas universidades (SANTHIAGO, 2018, p. 328).

Juniele Almeida (2016, p. 47), historiadora igualmente dedicada aos estudos e à realização de uma história pública, também ressalta que "no horizonte dos saberes dos movimentos sociais e da história oral, as práticas da história pública são evidenciadas nas interpretações dialógicas desse conhecimento histórico produzido e difundido". A historiadora destaca ainda que o processo da construção da entrevista surge das duas partes, ou seja, ocorre uma negociação de significados e sentidos entre entrevistador e entrevistado. A história oral possibilita, assim, a criação de fontes que expressam dimensões subjetivas de diferentes momentos históricos e busca, através da memória viva, a construção do vivido, ressaltando que a memória parte sempre do presente (ALMEIDA, 2016, p. 48-9).

A história do tempo presente também conquistou espaço nos últimos 20 anos. Ela possibilita que os historiadores pesquisem com um recuo menor de tempo, pois abordam eventos mais recentes. Além disso, a história do tempo presente tem promovido ampla renovação historiográfica, trazendo consigo a revitalização da história política, a ampliação do uso de fontes, a valorização da interdisciplinaridade e a recusa de explicações 
deterministas e totalizantes. Ela traz também a valorização de atores individuais e coletivos e a relação dialética entre história e memória (DELGADO; FERREIRA, 2014, p. 7).

Somado a isso, a história do tempo presente atua com a reelaboração e a reconfiguração de determinados acontecimentos históricos, mas, diferentemente dos períodos mais recuados, trabalha com um jogo de tensões, que operam não apenas diferentes visões de história e de historiadores, mas também dos personagens centrais dessa história. A história como campo de conhecimento é, então, marcada como espaço de travessias, lacerada por demandas inumeráveis. O passado é cada vez mais colocado como chave para a justificativa dos acontecimentos do dia a dia (MENESES, 2016, p. 70).

Em relação às pesquisas sobre música no campo historiográfico, há algum tempo trabalhos na área vêm sendo feitos. Desde 2007, os professores Adalberto Paranhos (UFU) e Tânia da Costa Garcia (Unesp/Franca) propõem na Associação Nacional de História (ANPUH) o Simpósio Temático História e Música. Entre as temáticas predominantes dos trabalhos temos a música no século XX, a indústria fonográfica, os movimentos musicais e as trajetórias de artistas. Em diversos desses trabalhos a MPB e seus integrantes e movimentos formadores têm destaque, entretanto, como já evidenciado, essas temáticas têm sido alargadas. Cabe lembrar que, se na década de 1960 a MPB não incorporava alguns artistas e movimentos, como a tropicália, esse movimento foi incorporado a ela na década seguinte. Em parte desses trabalhos, a história pública, a história do tempo presente e a história oral são elementos que compõem as análises das temáticas.

A sigla MPB tem se tornado cada vez mais abrangente e em alguns momentos tem sido redimensionada, talvez em função das diversas críticas que tem sofrido, como a do jornalista e historiador Paulo César Araújo, que em seu livro Eu não sou cachorro, não (2010), critica a exclusão dos artistas que seriam considerados "bregas" da história da música brasileira.

Para Araújo (2010, p. 343), essa “construção” da trajetória dos artistas vinculados à sigla funciona como uma invenção da tradição: esses artistas com destaque na década de 1970 seriam fruto dessa junção da "tradição" do samba de morro com o da "moderna" batida bossa-novista e as letras engajadas. Portanto, os descendentes dessa linha teriam destaque dentro do gênero MPB, sendo considerados os "fundadores" da sigla. 


\section{Leituras sobre a MPB em livros e projetos}

Cada vez mais historiadores produzem pesquisas que originam livros e que circulam não apenas na academia, mas também entre o grande público. Aqui, são analisados quatro trabalhos de historiadores, frutos de dissertações defendidas em programas de pósgraduação em história que foram transformados em livros e ampliaram sua circulação e público. O primeiro deles é o já citado Eu não sou cachorro, não, resultado da dissertação de mestrado em história defendido na Universidade Federal do Estado do Rio de Janeiro (UNIRIO) por Paulo César Araújo em 1999 — a obra foi lançada em 2002 e em 2010 já estava na sétima edição. O livro virou referência para quem tinha interesse de estudar fora do panteão da MPB. Redimensionando carreiras, Odair José, que até então tinha um público mais popular, começou a ser visto como um dos cantores mais censurados do regime militar e, assim, angariou um público universitário e teve diversos discos de carreira relançados em $\mathrm{CD}$ e plataformas digitais. O outro trabalho é o livro Solistas dissonantes, originário da dissertação defendida por Ricardo Santhiago no ano de 2009, no programa de história social pela Universidade de São Paulo (USP). O livro, lançado no mesmo ano, aborda a trajetória de 13 cantoras negras que não se vincularam ao gênero muitas vezes imposto para essas artistas, o samba. Outra obra é o livro Em busca do falso brilhante (2015), da historiadora Rafaela Lunardi, que aborda a trajetória de Elis Regina entre os anos de 1965 e 1976 e, como os demais citados, também é fruto de uma dissertação de pós-graduação em história social da USP, defendida em 2011. O último trabalho é o já mencionado livro de Gustavo Alonso que aborda a trajetória do cantor Wilson Simonal. Entre esses quatro trabalhos, três deles usaram entrevistas realizadas pelos autores como fontes - Rafaela Lunardi não fez entrevistas próprias, mas utilizou entrevistas de outros acervos para compor a obra. Outro aspecto interessante do trabalho dessa pesquisadora é que ela utilizou como fontes audiovisuais não apenas os DVDs de carreira, mas também vídeos do YouTube com a performance de artistas, explorando a multiplicidade das fontes do historiador do tempo presente. Se observarmos o currículo Lattes dos quatro autores aqui citados, todos apresentam, no item “entrevistas, mesas redondas, programas e comentários na mídia”, falas sobre os livros publicados, mostrando que a circulação foi além do espaço acadêmico. Quer 
dizer, todos os livros participaram do espaço público na elaboração e na difusão do conhecimento da temática que abordam.

Como exemplo prático de pesquisa acadêmica que transpõe os muros da universidade temos o trabalho da historiadora Sílvia Brügger. A professora da Universidade Federal de São João del-Rei iniciou, em 2002, um processo de catalogação e identificação do acervo da cantora Clara Nunes, que à época estava sob a guarda de sua irmã Maria Gonçalves, mais conhecida como Dindinha. Em 2004, ela iniciou o projeto de pesquisa sobre a cantora, intitulado $O$ canto do Brasil mestiço: Clara Nunes e o popular na cultura brasileira, para o qual a professora contou com bolsistas de iniciação científica. Entre os anos de 2007 e 2008, a historiadora fez seu pós-doutorado na Universidade Federal Fluminense (UFF), tendo a obra da cantora como tema. Na pesquisa, Brügger entrevistou dezenas de pessoas ligadas à artista, usando como sustentação a história oral. Ainda em 2008, ao lado de Marlon Silva, coordenou uma homenagem à Clara Nunes e deu consultoria para a montagem da exposição Brasil mestiço, ambos eventos do Inverno Cultural de São João del-Rei. No mesmo ano, lançou a coletânea $O$ canto mestiço de Clara Nunes (2008), que reúne textos de vários integrantes da pesquisa até aquele momento. Em 2012, foi inaugurado o Memorial Clara Nunes, na cidade de Caetanópolis (MG), resultado da parceria com o instituto Clara Nunes, presidido por Maria Gonçalves, e em 2014 foi a vez da exposição Clara Mestiça, montada por Sílvia Brügger e equipe e tendo Marlon Silva como curador. Hoje doutorando pela Universidade Federal de Minas Gerais (UFMG) e professor universitário, Silva iniciou sua carreira como bolsista de iniciação científica do projeto de Sílvia Brügger, que até hoje tem um projeto de extensão que contribui com a conservação do acervo, além de fazer parte do conselho de pesquisa do memorial.

O trabalho dessa professora é mais um exemplo de como um projeto acadêmico pode chegar ao público. Desde a inauguração, o memorial se tornou um dos pontos turísticos da cidade onde a cantora mineira nasceu. Além disso, a historiadora tem vasta produção acadêmica sobre a obra da artista, o que mostra que pesquisa e extensão andam lado a lado dentro da universidade.

Diante disso, o que destaco aqui é que os trabalhos saíram do circuito acadêmico e foram para o "público", evidenciando o potencial da temática que envolve a música popular 
brasileira. Esses trabalhos são apenas exemplos de como as pesquisas sobre a música brasileira tem transpassado as barreiras dos muros da universidade.

A história oral ajuda nessa ampliação, uma vez que muitos cantores e movimentos não têm suas trajetórias minuciosamente narradas por veículos da imprensa e por jornalistas e pesquisadores de outra área. É por meio da entrevista, então, que conseguimos entender trajetórias e momentos importantes da história da música brasileira. Por outro lado, temos um número grande de historiadores que, por questão de recursos, geografia ou falta de proximidade com a técnica, ou mesmo por acharem que os artistas não serão acessíveis, não conseguem (ou não tentam) enveredar pela história oral. E isso implica, muitas vezes, no foco nas trajetórias e movimentos que têm mais fontes acessíveis para a pesquisa.

\section{A música de: história pública da música brasileira}

A partir do panorama exposto e pensando em uma maneira de criar uma ponte de comunicação e trocas de ideias entre historiadores que trabalham com a temática da música popular brasileira - falando de sentido amplo, sem foco estrito na chamada MPB possibilitando acesso público, fácil e gratuito a entrevistas de artistas, produtores e músicos que fizeram a história da nossa música, preenchendo assim uma lacuna, surgiu a ideia da criação do site A música de: a história pública da música do Brasil ${ }^{41}$.

O projeto usa como base duas plataformas. A primeira é um site, no qual é possível ler resenhas de discos clássicos e de lançamentos feitas por historiadores ou pesquisadores ligados à academia. Com uma linguagem mais acessível, porém, sem prejuízo ao conteúdo, as resenhas têm de três a seis páginas. Entre os primeiros materiais resenhados, temos A noite do espantalho (1974), trilha de filme homônimo ao disco que traz as vozes de Sérgio Ricardo, Alceu Valença e Geraldo Azevedo. Escrita pelo historiador Rafael Hagemeyer, da Universidade do Estado de Santa Catarina (UDESC), a resenha tem como

\footnotetext{
${ }^{41}$ O projeto foi idealizado conjuntamente por mim, Autor, e por Ricardo Santhiago que somos os coordenadores. Na equipe como editores de seção temos os historiadores Nashla Dahás e Carlos Eduardo Pereira de Oliveira. O site conta também com artes da ilustrado Thaís Mesquita, e tem os vídeos editados pelo estudante de cinema Raffael Righez.O site ainda conta com colaboradores de diversas universidades do Brasil.
} 
fonte entrevistas que ele fez para um documentário sobre o cinema de Sérgio Ricardo. Já o disco Fátima Guedes (1980) teve sua resenha feita pelo doutor em letras pela Universidade Federal do Rio de Janeiro (UFRJ) Jorge Luiz Moraes, enquanto Tubarões voadores (1984), de Arrigo Barnabé, foi resenhado pelo professor da Universidade Estadual Paulista (UNESP/Franca) José Adriano Fenerick. No campo dos lançamentos, temos como exemplos Amor é isso (2018), disco de Erasmo Carlos resenhado pelo doutorando em história da UDESC Carlos Eduardo Pereira de Oliveira e Viola perfumosa (2018), de Lui Coimbra, Ceumar e Paulo Freira, resenhado pelo professor da Universidade Federal de Uberlândia (UFU) Haroldo de Resende. Ao citar alguns dos discos resenhados, atentamos para a pluralidade dos gêneros musicais, pois a ideia do site é poder abarcar uma base de dados mais abrangente possível, que não foque apenas nos discos considerados clássicos e, muitas vezes, já trabalhados em exaustão em pesquisas acadêmicas.

A segunda plataforma usada pelo projeto é o YouTube, na qual são publicadas entrevistas com a trajetória de vida de artistas ligados à música brasileira. Como baliza para isso usamos a história oral e, a partir de uma extensa pesquisa realizada sobre a vida artística do entrevistado, é montado um roteiro para que ele tenha a possibilidade de abordar diferentes aspectos de sua trajetória. As entrevistas são agendadas a cabe ao artista escolher o lugar onde quer concedê-la. Sem horário delimitado, é ele também quem decide a duração, uma vez que tudo depende de suas respostas e da vontade e disponibilidade de falar. Na edição, são decididas em quantas partes a entrevista será dividida e são introduzidas fotos, canções citadas pelo entrevistado e vídeos de momentos artísticos do depoente.

Os vídeos com os quatro primeiros entrevistados foram lançados no mês de maio de 2019. Os protagonistas dos depoimentos foram Théo de Barros, Martinha, Zé Luiz Maziotti e Edy Star. Em julho foi lançada a entrevista com Claudette Soares e, em setembro, foi a vez da entrevista com a cantora Eliana Pittman ser disponibilizada no site. Portanto, vemos artistas que comtemplam MPB engajada, Jovem Guarda, rock, bossa nova e outros movimentos e grupos da canção nacional. Desde o lançamento, o site contabiliza 38.878 minutos de exibição, com 6.911 visualizações ${ }^{42}$. A ideia aqui não é pensar esses dados

\footnotetext{
${ }^{42}$ Acesso aos dados do YouTube Estúdio Beta em 03 de novembro de 2019.
} 
quantitativamente, mas, sim, tentar observar se o canal tem conseguido se comunicar com diferentes públicos.

A entrevista não acontece em um formato como costumamos ver em um talk show, pois para a câmera apenas o artista e suas respostas têm destaque - as vozes dos entrevistadores poucas vezes aparecem. Os vídeos, além de entrevistas usuais, também podem ser usados pelos historiadores como uma espécie de banco de dados, porque ao tentar comtemplar a trajetória total do artista, o material vira uma fonte para um possível pesquisador ao mesmo tempo em que tem um caráter contemplativo para fãs dos artistas que aparecem na tela. Ou seja, o objetivo é comtemplar tanto acadêmicos quanto o grande público. Pelos comentários nos vídeos, podemos perceber que existe uma lacuna, ou uma falta de espaço, nas mídias atuais para esses artistas, o que faz com que espectadores - em geral, admiradores dos narradores — citem a importância do depoimento que está na tela.

Na entrevista de Théo de Barros, por exemplo, temos o seguinte comentário: “THEO DE BARROS é um GIGANTE da MPB! = MARAVILHOSO! Tem belas músicas interpretadas pela maior cantora do Brasil, a gigante ELIS REGINA”. No vídeo de Martinha, por sua vez, vemos o comentário "Belas tardes de Domingo... quantas alegrias!!! Bom te ver Martinha... belos tempos... belos dias". No de Zé Luiz Mazziotti, temos "Um registro fantástico, de um artista sem igual", e na entrevista de Edy Star, "Maravilhoso, inteligente e uma memória esplendorosa! Te amamos Edy" e "Top demais, salve salve Edy Star. Parabéns a todos os envolvidos!" ${ }^{43}$. Esses são alguns dos comentários deixados nos vídeos, que vão desde a valorização do trabalho do artista que ali está narrando sua trajetória de vida até um saudosismo em relação ao tempo vivido e à valorização do trabalho da equipe.

Uma das perguntas fixas do roteiro é, talvez, a mais capciosa, pois questiona como os artistas gostariam de ser lembrados na história da música brasileira. A questão, que gera dúvidas em alguns momentos e silêncio em outros, por vezes demora a ser respondida por ser algo imprevisto, demandando espontaneidade e doses de criação.

\footnotetext{
${ }^{43}$ Comentários dos vídeos consultados em 5 de agosto de 2019.
} 
Mesmo em estágio inicial, o site tem possibilitado uma constituição de uma rede de pesquisadores no país que tem trabalhado com a história da música. Por esse motivo, há no portal um espaço em que são colocadas pesquisas de mestrado e doutorado que têm ligação com a temática ligada à música. Com isso, temos o intuito de não apenas montar esse banco de dados, mas também de ser também um canal que divulga para o grande público trabalhos que tantas vezes ficam apenas vinculados ao meio acadêmico.

Usamos ainda como ferramenta de divulgação dos trabalhos as redes sociais Instagram e Facebook, que possibilitam a difusão do conteúdo feito pelo projeto. Há também uma frente de entrevistas que conta com nomes como Jane Moraes, Claudya, Maria Alcina e Luiz Ayrão, e que serão divulgadas nos próximos meses, que mostra mais uma vez a ideia plural do site de entrevistar artistas dos mais variados estilos musicais.

\section{Edy Star e as memórias da infância}

Um dos nossos primeiros entrevistados foi o cantor Edy Star. Nascido em Juazeiro (BA), em 1938, o cantor começou cedo na vida artística. Na década de 1960, fez teatro amador em Salvador. Além disso fez parte da Companhia Baiana de Comédia (CBC). Em 1967, em Recife (PE), participou do musical Memória de dois cantadores, ao lado de Teca Calazans, Geraldo Azevedo e Naná Vasconcelos. Trabalhou na televisão de Recife e de Salvador (BA) e, em 1970, a convite de Raul Seixas, foi contratado pela Columbia (CBS), gravadora na qual fez um compacto simples. Em 1971, foi parte do clássico disco Sociedade da Grã-Ordem Kavernista apresenta sessão das 10, com Sérgio Sampaio, Raul Seixas e Míriam Batucada. Em 1974, contratado pela Som Livre, lançou Sweet Edy. Depois de décadas morando fora do país, o cantor retornou ao Brasil e, em 2017, lançou do CD Cabaré star, produzido por Zeca Baleiro ${ }^{44}$.

A entrevista com o performer foi realizada em um sábado, dia 2 de novembro de 2018, e teve duração de mais de três horas, nas quais o cantor narrou sua trajetória de vida, da infância aos dias atuais. Para o site, a entrevista foi dividida em cinco partes, porém, aqui, vamos abordar somente a primeira delas, em que o artista aborda sua infância, influências

\footnotetext{
${ }^{44} \mathrm{http} / / /$ dicionariompb.com.br/edy-star/dados-artistico
} 
musicais e início da carreira. Essa primeira parte entrou no ar dia $1^{\circ}$ de maio de 2019 e acumula 305 visualizações ${ }^{45}$.

O cantor, desde o início, mostrou-se animado ao narrar de forma abrangente sua trajetória de vida, diferentemente do que ocorre nas entrevistas jornalísticas, que são mais curtas e estão interessadas em aspectos específicos. A entrevista para o site, contudo, tinha o objetivo de provocar a memória que o artista poderia elaborar de sua trajetória total. Como já indicamos, as entrevistas têm um roteiro prévio, com um número similar de perguntas a todos os entrevistados, e quem decide a duração da entrevista são eles, de acordo com suas respostas e disponibilidade de falar. A primeira pergunta feita a Edy Star foi: quais eram suas influências musicais? E ele respondeu assim:

Eu sou de uma época da Rádio Nacional, da Rádio Maria (inaudível), então a minha cultura, como a cultura das pessoas, não só das pessoas da Bahia, mas das pessoas da época, é uma cultura de rádio. São os cantores daquela época, os cantores Antônio Sérgio, Francisco Alves, Vicente Celestino, Silvio Caldas, entende? O pessoal que logo veio depois: o sucesso Luiz Gonzaga, Carmélia Alves. Vem o pessoal que fazia os boleros da época: Emilinha Borba, o pessoal da Rádio Nacional de samba, Marlene, Carmem Costa, Linda Batista, Dircinha Batista. Então a minha influência toda é deste pessoal. Influência do que eu considero a boa, "BM", boa música popular brasileira, você entende? A minha influência é toda essa (EDY STAR, 2018).

Em seguida, perguntamos ao artista se ele tinha familiares ligados à carreira

artística:

\begin{abstract}
Na minha família não tinha ninguém artista. Ninguém nunca foi contra eu ser artista, anos depois, nunca foi contra pelo motivo e incentivo de tentar, que eu cantava sempre, cantava em casa e armava circo, imitava os programas de rádio que eu não sabia como que era, mas eu sempre fazia em casa, eu via fotografias do pessoal sentado com a mesa dentro. Então eu fazia na minha casa, brincava com a minha irmã e com o meu irmão de rádio, de artista de rádio e cantava as músicas do rádio. Mas na minha família nunca teve, eu nunca sofri. Contra? Nada, nada. Mas não tem nenhum artista que tocava, não tinha. Tinha o meu pai de ouvir muita música (EDY STAR, 2018).
\end{abstract}

Se em um primeiro momento, ao falar de suas influências musicais, Edy Star citou nominalmente diversas pessoas da Era do Rádio, mostrando um conhecimento e uma

\footnotetext{
${ }^{45}$ Consulta feita no dia 9 de outubro de 2019.
} 
lembrança de artistas que o influenciaram na música, depois ele lembrou que, mesmo não tendo familiares ligados à trajetória artística, não houve movimento contrário quando ele resolveu seguir essa carreira. $\mathrm{O}$ artista disse ainda que sua casa era musical, que seu pai sempre foi muito ligado à música. E seguiu falando do gosto musical do pai:

Meu pai era fã de Luiz Gonzaga, era fã de um cantor do Rio Grande do Sul chamado Pedro Raimundo que tinha uma música chamada "Adeus Mariana que eu já vou me embora". Entendeu? Eu tive uma conversa sobre isso com a banda Cachorro Grande. Disse: "Edy, você conhece isso?"4"; e eu disse "conheço, porque isso é anterior ao Teixerinha" (EDY STAR, 2018).

Em seguida, Edy, ou Edivaldo Souza — seu nome de batismo - , narrou seus primeiros passos na trajetória artística:

\begin{abstract}
Havia um programa... Olha que loucura. Olha que loucura! Que coincidência que vai acontecer agora. Havia um programa em Salvador chamado Hora da Criança, que era feito pelo professor Adroaldo Ribeiro Costa, que tinha uma ideia de fazer um programa para crianças, por crianças. Então as crianças lá cantavam muito mais coisas de folclore, de cantigas de roda do que músicas populares. As músicas populares não podiam ferir uma certa ética, que hoje não poderia produzir porque hoje não tem ética nenhuma. Então esse programa ali eu conheci o pessoal do Quarteto em Cy, que foi introduzido nesse programa também. Cyva e Cybele, eu cheguei a fazer trio com Cyva e Cybele. Que eram irmãs chamadas Cyva, Cybele, Cynara e Cylene. São as quatro irmãs. E hoje em dia eu me correspondo com Cyna e Cynara. Cybele já foi... Todos da mesma época e por coincidência eu saí para tirar xerox... Olha a carteirinha da Hora da Criança... Cyva não tem isso. Eu vou até tirar para mostrar pra Cyva.
\end{abstract}

Coincidentemente ou não, Edy Star estava com a carteirinha do programa e, durante a entrevista, foi possível observar que o artista é guardião não apenas de sua memória, mas também de seu acervo, tendo guardado muitas coisas no decorrer da sua carreira. Além disso, nesse momento ele lembrou da amizade com as irmãs baianas que fizeram sucesso ainda na década de 1960, com Quarteto em Cy. A memória do programa é afetiva, ligando Edy Star à sua terra natal, ao seu momento de criança e, ainda, ajudando a desenvolver sua linha narrativa da trajetória artística, do garoto que ainda criança já despontava nas artes em Salvador.

Tinha esse programa e eu queria cantar. Meu pai me levou para cantar nesse programa. Ele me levou e eu comecei a cantar. Era um programa feito por crianças, programa de rádio, e que o professor também fazia montagens teatrais. Fazia

${ }^{46} \mathrm{O}$ cantor refaz a pergunta que algum artista da banda fez para ele. 
operetas baseadas nas obras de Monteiro Lobato. Que fez muito sucesso ele fez Narizinho, que era baseado em Narizinho: a menina do nariz arrebitado. Uma opereta, com música do professor Agenor Gomes e os meninos ensaiavam para fazer essas obras. Então era assim: 150, 200 crianças no palco fazendo isso. Tinha os papéis principais, naturalmente, quem tinha a melhor voz, e tinha o coral (EDY STAR, 2018).

Quando você tinha 15 anos você tinha que sair, porque você não era mais criança, entende? Então tinha uma coisa de adeus... "adeus, adeus". Foi muito triste, as pessoas choravam, era um inferno aquilo. Então (inaudível) foi indo, indo e entrando pessoas novas... Eu saí dali e já fui pegar os meus estudos, e "vamos cantar", “onde é que eu vou cantar?". Comecei a cantar na Rádio Sociedade da Bahia, num programa à tarde, que era o Programa JS, e já estava praticamente chegando à televisão na Bahia. A Rádio Cultura da Bahia, que aí eu já encontrei Raul. Reencontrei Raul porque eu já conhecia Raul Seixas de outros carnavais, muito lá atrás. Já cantei com Raul e seus Panteras no programa, que era um programa chamado "só para mulheres", que era um programa diário, de estúdio, mas no sábado era um programa de auditório (EDY STAR, 2018).

Nos trechos seguintes, o cantor explicou como funcionava o programa e o momento da despedida e, em seguida, relatou que, ao ter que sair do programa, começou a buscar novos espaços artísticos. Cabe aqui fazer uma referência à questão da memória, destacada por Daphene Patai (2010, p. 30):

Do imenso depósito de memória e reações possíveis evocadas pela situação da entrevista, o entrevistado seleciona e organiza temas, episódios e lembranças, então comunicando de maneira particular. Sem dúvida, a memória em si é gerada e estruturada de maneira específica, em função da oportunidade de contar uma história de vida e das circunstancias que isso acontece. Em outro momento de vida, ou diante de outro interlocutor, é provável que surja uma história bem diferente, com ênfases diferentes.

$\mathrm{Na}$ entrevista com Edy Star foi possível observar que o artista entendeu, naquele momento, que o trabalho feito por dois historiadores tinha interesse em ser mais do que anedótico ou factual, tentando, dentro do possível, trazer aspectos da carreira do cantor desde os de maior conhecimento público aos não tão conhecidos. E foi dessa maneira que a entrevista fluiu, com um entrevistado interessado em resgatar sua trajetória e com entrevistadores ávidos para transformar aquela narrativa em história pública. 


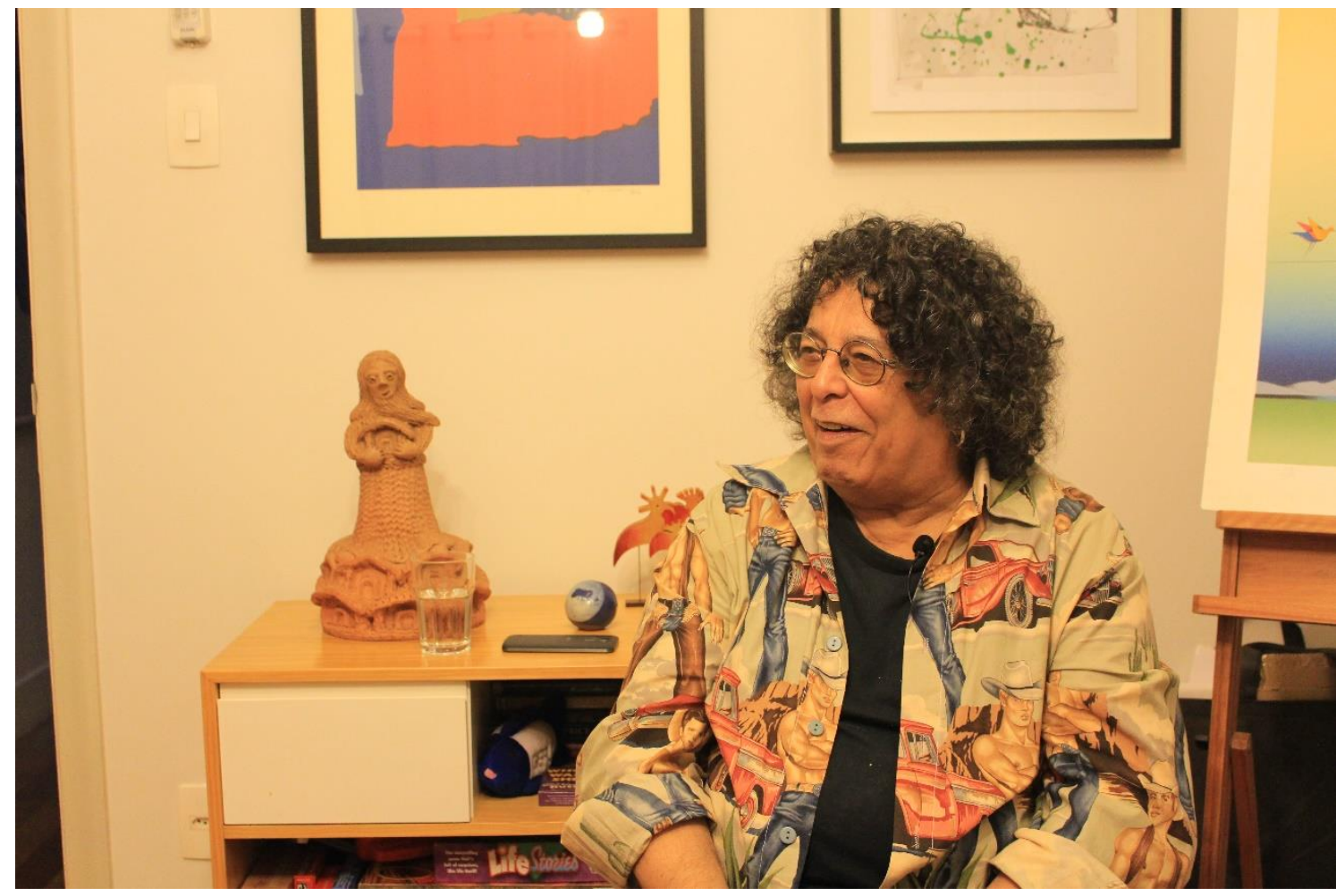

Edy Star em entrevista para o site A Música de. História Pública da Música do

Brasil

O cantor seguiu narrando sua trajetória, falando sobre as amizades que fez na Bahia, seu trabalho na Petrobras e de quando abandonou o "emprego dos sonhos" para se dedicar apenas à carreira artística:

Eu tinha conhecido Gilberto Gil, tinha conhecido o Glauber, tinha conhecido o pessoal e encontrava com esse pessoal à noite quando eu saía da escola. Eu estudava à noite. Já tinha repetido o ano duas vezes e meu pai já não aguentava mais pagar escola particular para mim e eu fui estudar num colégio estadual, chama-se estadual, que era colégio público e eu saía do colégio às dez da noite. Então eu vinha para o centro da cidade e encontrava essa turma, que era uma turma de boêmia completa e a gente passava de puteiro em puteiro, vamos dizer assim, de cabaré em cabaré, cantando (EDY STAR, 2018).

Eu trabalhava na Petrobras. Passei um ano trabalhando na Petrobras e eu era praticamente um rei, praticamente um rei na minha casa, porque eu ganhava quatro, cinco vezes o que meu pai ganhava. Trabalhava num campo de Dom João, campo de Dom João era campo de petróleo de Dom João, da cidade de Dom João. Lá eu tinha direito a um jipe, tinha direito a motorista, roupa lavada. Tinha que passar por... São dez serviços na produção, porque o petróleo tem duas coisas, que é 
produção e perfuração. Um ano e um mês; eu disse "chega". Porque eu só queria mostrar à minha família que eu podia trabalhar (EDY STAR, 2018).

Alessandro Portelli (2016, p. 18) nos lembra que quando trabalhamos com fontes orais devemos traçar um caminho complexo, cobrindo três níveis distintos, mas interconectados: "Um fato do passado (o evento histórico), um fato do presente (a narrativa que ouvimos) e uma relação fluida, duradoura (a interação entre esses dois fatos)". O trabalho do historiador oral envolve, então: 1 - A historiografia no sentido tradicional (a reconstrução de eventos passados); 2- A antropologia, a análise cultural e a crítica textual (a interpretação da entrevista); e 3 - O espaço intermediário (como esses eventos produzem determinada memória e determinada narrativa).

Ainda segundo Portelli (2016, p. 18), “a memória, na verdade, não é um mero dispositivo de informação, mas um processo contínuo de elaboração e reconstrução de significado". Quer dizer, a história oral é não apenas a história dos eventos, mas também a história da memória e a história da interpretação dos eventos através da memória.

E é partindo desse ponto que o site A música de trabalha, buscando através da memória a história de trajetórias de atores da música brasileira. Como podemos ver na entrevista de Edy Star, a memória é evocada para narrar sua história, elaborada de forma cronológica, do passado ao futuro, com o intuito de trazer à tona a trajetória artística de um cantor que, por vezes, ainda não recebeu a merecida atenção da historiografia da cultura brasileira.

O site funciona como um emaranhado de memórias sobre a música brasileira, que vai sendo construído não de forma conjunta, entre entrevistadores e entrevistados, mas da junção da necessidade de ouvir com a possibilidade de contar. Nesse sentido, a entrevista de Edy Star é simbólica, pois o site não estava no ar e era uma incógnita como seriam os andamentos das entrevistas — o artista foge das entrevistas "padrão", geralmente feitas por jornalistas, o que possibilita de uma só vez, ao espectador leigo, compreender a trajetória do artista e do público acadêmico e observar as redes de sociabilidades dele, as mudanças no meio e na indústria musical durante as décadas, a entender aspectos da censura comportamental, assim como observar a trajetória de um artista que não teve sua história narrada de forma ampla em um livro ou em outras plataformas. 


\section{Considerações finais}

Como observamos, a história pública tem conquistado espaço entre os historiadores brasileiros nas últimas décadas. Por conta da necessidade de fazer com que o conhecimento produzido dentro da universidade ganhe uma plateia maior, tem feito parte da rotina dos historiadores colocarem como horizonte de seus trabalhos essa interlocução entre academia e público. Há diversos historiadores que vêm conectando suas pesquisas sobre história da música e história pública. Nesse movimento, o site A música de: história pública da música do Brasil busca essa junção, a fim de conseguir ser um trabalho para um público amplo, mas sem perder o rigor acadêmico.

E é nessa busca que vem sendo construído esse trabalho, seja na construção da rede de parceiros e pesquisadores da área, seja na metodologia da elaboração das entrevistas e no contato com artistas. Mesmo que ainda esteja em processo inicial, o projeto tem em seu embrião o caráter coletivo, uma vez que depende de vários pesquisadores para seu sucesso e que, desde a elaboração, foi montada uma equipe e foram convidados pesquisadores de diferentes instituições. O projeto oferece a formação de uma base de dados de entrevistas e resenhas feitas por acadêmicos que têm como interesse buscar uma multiplicidade de artistas e gêneros a serem pesquisados. Além disso, evita uma hierarquização dos entrevistados e busca sujeitos que poucas vezes tiveram a oportunidade de falar sobre suas trajetórias de forma integral.

\section{REFERÊNCIAS}

ALEXANDRE, Ricardo. Não vem que não tem: a vida e o veneno de Wilson Simonal. São Paulo: Globo, 2009.

ALMEIDA, Juniele Rabêlo de. Práticas de história pública: o movimento social e o trabalho de história oral. In: ALMEIDA, Juniele Rabêlo de; MAUAD, Ana Maria;

SANTHIAGO, Ricardo (org). História pública no Brasil: sentidos e itinerários. São Paulo: Letra e Voz, 2016.

ALONSO, Gustavo. Simonal: quem não tem swing morre com a boca cheia de formiga. Rio de Janeiro: Record, 2011. 
ARAÚJO, Paulo César. Eu não sou cachorro, não. Rio de Janeiro: Record, 2002.

BAIA, Silvano Fernandes. A historiografia da música popular no Brasil. Uberlândia: EDUFU, 2015.

BRÜGGER, Silvia Maria Jardim. O canto mestiço de Clara Nunes. São João del-Rei: MG: UFSJ, 2008

DELGADO, Lucilia de Almeida Neves; FERREIRA, Marieta de Moraes(org.). História do tempo presente. Rio de Janeiro: FGV, 2014.

HERMETO, Miriam. Canção popular brasileira e ensino de história: palavras, sons e tantos sentidos. Belo Horizonte: Autêntica Editora, 2012.

LUNARDI, Rafaela. Em busca do falso brilhante: performance e projeto autoral na trajetória de Elis Regina (Brasil, 1964-1976). São Paulo: Intermeios, 2015.

MENESES, Sônia. As dimensões públicas da história: sobre pensar a memória e o esquecimento na era do Google. In: SILVA FILHO, Antonio Luiz Macêdo; RIOS, Kênia Sousa(org). Tempo, cultura e memória. Fortaleza: Expressão Gráfica Editora, 2016.

NAPOLITANO, Marcos. História \& Música: história cultural da música popular. Belo Horizonte: Autêntica, 2005.

PATAI, Daphne. História oral, feminismo e política. São Paulo: Letra e Voz, 2010.

PORTELLI, Alessandro. História oral como arte de escuta. São Paulo: Letra e Voz, 2016. SANTHIAGO, Ricardo. Solistas dissonantes: história(oral) de cantoras negras. São Paulo: Letra e Voz, 2009. Pode-se falar em história pública brasileira? In: SANTHIAGO, R; MAUAD, A.M; BORGES, V. Que história pública queremos. São Paulo: Letra e Voz, 2018.

Sites:

http://amusicade.com/

http://dicionariompb.com.br

Entrevista: 
Entrevista de Edy Star concedida aos pesquisadores Autor e Ricardo Santhiago no dia 2 de novembro de 2018, na cidade de São Paulo. Duração: 03h39min58seg 